\title{
Prophylactic Oral Administration of Magnesium Ameliorates Dextran Sulfate Sodium-Induced Colitis in Mice through a Decrease of Colonic Accumulation of P2X7 Receptor-Expressing Mast Cells
}

\author{
Kenshi Ohbori, ${ }^{a}$ Makiko Fujiwara, ${ }^{a}$ Akihiro Ohishi, ${ }^{a}$ Kentaro Nishida, ${ }^{a}$ Yoshinobu Uozumi, ${ }^{b}$ and \\ Kazuki Nagasawa*,a \\ ${ }^{a}$ Department of Environmental Biochemistry, Kyoto Pharmaceutical University; 5 Nakauchi-cho, Misasagi, \\ Yamashina-ku, Kyoto 607-8414, Japan: and ${ }^{b}$ Technical Development Department, Ako Kasei Co., Ltd.; 329 Sakoshi, \\ Ako 678-0193, Japan.
}

Received February 13, 2017; accepted April 13, 2017

\begin{abstract}
The number of patients with colitis has been increasing year by year. Recently, intestinal inflammation, as one of the factors for its onset, has been demonstrated to be induced by $\mathrm{P} 2 \mathrm{X} 7$ receptor-mediated activation of colonic immune cells such as mast cells. Activation of $P 2 X 7$ receptor (P2X7R) is known to be inhibited by divalent metal cations such as magnesium, but whether or not magnesium administration prevents/relieves colitis is unknown so far. Here, we report that oral (per os (p.o.)) administration of $\mathrm{MgCl}_{2}$ and ingestion of commercially available magnesium-rich mineral hard water relieves dextran sulfate sodium (DSS)-induced colitis in mice. Colitis was induced through ingestion of a $3 \%(w / v)$ DSS solution ad libitum for $10 \mathrm{~d}$. Brilliant blue G (BBG, a P2X7R antagonist), $\mathrm{MgCl}_{2}$ or magnesium-rich mineral hard water was administered p.o. to mice via gastric intubation once a day or ad libitum from a day before DSS administration for 11 times or $11 \mathrm{~d}$, respectively. DSS-treated mice exhibited a low disease activity index, a short colon and a high histological score compared to in control mice. As BBG $\left(250 \mathrm{mg} / \mathrm{kg}, \mathrm{p.0}\right.$.), administration of a $\mathrm{MgCl}_{2}$ solution $(100$ or $500 \mathrm{mg} / \mathrm{kg}$, p.o.) and ad libitum ingestion of the magnesium-rich mineral hard water (212 ppm as magnesium) partially, but significantly, attenuated the severity of colitis by decreasing the accumulation of P2X7R-immunopositive mast cells in the colon. Therefore, prophylactic p.o. administration/ingestion of magnesium is considered to be partially effective to protect mice against DSS-induced colitis by inhibiting P2X7R-mediated activation/accumulation of colonic mast cells.
\end{abstract}

Key words magnesium; colitis; inflammatory bowel disease; mast cell; P2X7 receptor

Crohn's disease and ulcerative colitis are the two major clinical forms of inflammatory bowel disease (IBD), and are characterized by chronic and relapsing inflammation of the gastrointestinal tract. ${ }^{1,2)}$ Although the pathogenesis of IBD is rather complex, evidence indicates the concomitant involvement of a genetic predisposition, environmental triggers, microbial agents, and immune dysfunction as essential factors for disease development. ${ }^{3,4)}$ Recent studies have demonstrated that excessive activation of immune cells such as macrophages and helper $\mathrm{T}$ cells in the intestine and colon is a determinant of the course of IBD progress, because these activated immune cells release large amounts of inflammatory cytokines and bioactive molecules. ${ }^{5-7)}$ Thus, these immune cells are accepted to be a potential target for the treatment of IBD.

Purinergic signaling is an important component of host defense against pathogens, mainly through activation of P2 receptors. ${ }^{8}$ ) Of them, $\mathrm{P} 2 \mathrm{X} 7$ receptor (P2X7R), an ionotropic receptor, is expressed on epithelial cells and immune effector cells such as macrophages and mast cells, and is involved in the regulation of pro-inflammatory cytokines. ${ }^{9-12)}$ Under inflammatory conditions, activation of immune cells and injury of cells induces excessive release of ATP, by which the local concentration of ATP in a tissue is drastically increased up to $\mathrm{mm}$ level, ${ }^{13,14)}$ resulting in exacerbation of inflammation via activation of P2X7R. ${ }^{14,15)}$ In fact, systemic blockade of P2X7R is reported to be effective for prevention of experimental colitis. ${ }^{16-18)}$

Kurashima et al. demonstrated that intraperitoneal (i.p.) prophylactic administration of $\mathrm{P} 2 \mathrm{X} 7 \mathrm{R}$-specific monoclonal antibodies apparently prevented the development of experimental colitis in mice by decreasing the accumulation of P2X7R-expressing mast cells in the colon. ${ }^{16)}$ In addition, Marques et al. reported that i.p. administration of P2X7R antagonists exhibited partial, but significant, prophylactic effects on experimental colitis in rats, ${ }^{17)}$ and almost the same finding was obtained in mice by Wan et al. ${ }^{18)}$ Interestingly, in the study of Kurashima et al., it was clearly indicated that ATPP2X7R-mediated activation of colonic mast cells followed by their accumulation in the colons is the initiation phase of colitis development by induction of not only inflammatory cytokines, but also chemokines and leukotrienes for infiltration of neutrophils into the colon, leading to subsequent exacerbation of intestinal inflammation. ${ }^{16)}$ Based on this, it is reasonable to consider that prophylactic oral per os (p.o.) administration of P2X7R blockers can prevent the development of experimental colitis by inhibiting the initiation of inflammation cascade induced by the P2X7R-mediated activation of colonic immune cells such as mast cells. However, there has been no report on the effect of p.o. administration of P2X7R blockers on experimental colitis.

It is well known that divalent metal cations (DMCs) have inhibitory effects on activation of P2X7R. ${ }^{19-22)}$ Recently, we revealed that the inhibitory effects of DMCs were greater in the order of copper $>$ zinc $\approx$ nickel $\approx$ magnesium $>$ calcium for both human and mouse P2X7Rs, and that there was species differences in the effects of nickel and calcium, but not of 
the others, between humans and mice. ${ }^{23)}$ Of these DMCs, we have focused on magnesium as a blocker for P2X7R activation because magnesium oxide, which gives magnesium chloride by reacting with gastric acid in the stomach, is used as a medicine for gastritis/gastric ulcers and constipation, guaranteeing safety and colonic delivery of magnesium via p.o. administration, and has a relatively greater inhibitory ability as to $\mathrm{P} 2 \mathrm{X} 7 \mathrm{R}$ activation (the $\mathrm{IC}_{50}=0.3-0.4 \mathrm{~mm}$ as $\mathrm{MgCl}_{2}$ ), compared to the case of calcium $\left(\mathrm{IC}_{50}\right.$ value $=2$ or more $\mathrm{mM}$ as $\left.\mathrm{CaCl}_{2}\right){ }^{23)}$ In addition, magnesium at concentrations found in vivo inhibited agonist-induced $\mathrm{P} 2 \mathrm{X} 7 \mathrm{R}$ activation in vitro experiments, ${ }^{19,21)}$ while the other P2XRs, except for P2X1R, are known to be potentiated or unaffected by DMCs. ${ }^{24-30)}$ Therefore, there is the possibility that DMCs might exhibit specific antagonism as to P2X7R without any effect on other P2XRs. Thus, we postulated that p.o. administration of magnesium might prevent P2X7R-mediated experimental colitis in mice.

On the market, there are a lot of mineral hard waters, the majority of which contains higher concentrations of calcium (180-530 ppm) than magnesium (50-100 ppm). In a commercially available refined deep-seawater (RDSW), in contrast, the concentration of magnesium is $212 \mathrm{ppm}(8.72 \mathrm{~mm})$, which is higher than that of calcium $(73.8 \mathrm{ppm}(1.85 \mathrm{~mm})),{ }^{31)}$ and is approximately 40 -fold greater than the $\mathrm{IC}_{50}$ value for $\mathrm{P} 2 \mathrm{X} 7 \mathrm{R}$, there being the possibility to prevent $\mathrm{P} 2 \mathrm{X} 7 \mathrm{R}$ activation expressed by colonic immune cells through its ingestion.

Therefore, we investigated whether or not p.o. administration of a $\mathrm{MgCl}_{2}$ solution, and ad libitum ingestion of a $\mathrm{MgCl}_{2}$ solution and RDSW had prophylactic effects on the development of dextran sulfate sodium (DSS)-induced experimental colitis in mice.

\section{MATERIALS AND METHODS}

Chemicals In this study, to induce experimental colitis, we used dextran sulfate sodium salt (colitis grade) (Cat. and Lot Nos.: 160110 and Q3526, respectively, molecular weight $(\mathrm{MW})=36000-50000$, MP Biomedicals, LLC, OH, U.S.A.). As commercially available magnesium-rich mineral hard water, RDSW (Amami's Water ${ }^{\circledR} /$ Water Hardness 1000, Ako Kasei Co., Ltd., Ako, Japan) was used, its ingredients being as follows: magnesium (212 ppm), calcium (73.8 ppm), sodium $(60.1 \mathrm{ppm})$ and potassium $(57.5 \mathrm{ppm}){ }^{31)}$ Brilliant blue $\mathrm{G}$ (BBG) and $\mathrm{MgCl}_{2} \cdot 6 \mathrm{H}_{2} \mathrm{O}$ were purchased from Sigma-Aldrich Co. (St. Louis, MO, U.S.A.), and Wako Pure Chemical Industries, Ltd. (Osaka, Japan), respectively. All other chemicals and reagents were purchased commercially and were of analytical grade requiring no further purification, except where otherwise noted.

Animals All experiments were approved by the Experimental Animal Research Committee of Kyoto Pharmaceutical University (Permit No.: 16-13-033), and were performed according to the Guidelines for Animal Experimentation of Kyoto Pharmaceutical University. Female C57BL6/Ncrl mice (7 or 8 weeks-old, Charles River, Yokohama, Japan) housed with food and water available ad libitum in a controlled environment with a $12 \mathrm{~h} / 12 \mathrm{~h}$ light/dark cycle were used.

Induction of Colitis and Experimental Protocol Following a generally accepted protocol, ${ }^{32)}$ to induce the experimental colitis in mice, they were allowed to ingest a $3 \%(\mathrm{w} / \mathrm{v})$ DSS solution in distilled water ad libitum for $10 \mathrm{~d}$ (from days 0 to 10$)$.
Administration Protocol BBG, a specific antagonist for $\mathrm{P} 2 \mathrm{X} 7 \mathrm{R},{ }^{33)}$ and $\mathrm{MgCl}_{2}$ were dissolved in distilled water at the concentrations of $10 \mathrm{mg} / \mathrm{mL}$ and 5 or $25 \mathrm{mg} / \mathrm{mL}$, respectively, and then administered to mice p.o. at the doses of $250 \mathrm{mg} / \mathrm{kg}$ and 100 or $500 \mathrm{mg} / \mathrm{kg}$, respectively, once a day from a day before initiation of DSS treatment (day -1) to day 9, i.e., for 11 times. With the BBG group acting as a positive control, we preliminarily evaluated its inhibitory effect on DSS-induced colitis at 100,250 and $500 \mathrm{mg} / \mathrm{kg}$ by p.o. and i.p. administration following the reports of Marques et al. ${ }^{17)}$ and Apolloni et al., ${ }^{34)}$ and its optimum dose was judged to be $250 \mathrm{mg} / \mathrm{kg}$ (p.o.) (data not shown). As for the doses of $\mathrm{MgCl}_{2}$, we also confirmed in preliminary experiments that p.o. administration of a $\mathrm{MgCl}_{2}$ solution at the dose of 500 or less $\mathrm{mg} / \mathrm{kg}$ did not induce diarrhea in mice (data not shown), and thus its doses were determined to be 100 or $500 \mathrm{mg} / \mathrm{kg}$.

In the cases of ad libitum ingestion, mice had free access to a $\mathrm{MgCl}_{2}$ solution or RDSW as drinking water from day -1 to day 10 , i.e., for $11 \mathrm{~d}$. The concentration of $\mathrm{MgCl}_{2}$ in the drinking water was set at $800 \mathrm{ppm}$, which corresponded to the magnesium concentration in RDSW (212 ppm), as stated above, and the mice that ingested the $\mathrm{MgCl}_{2}$ solution and RDSW were confirmed to exhibit no diarrhea (data not shown). For DSS-treated mice, $\mathrm{MgCl}_{2}$ dissolved in 3\% DSS solution and $3 \%$ DSS in RDSW were used. In the preliminary experiments, the daily drinking volume for these mice was approximately $4 \mathrm{~mL} / \mathrm{mouse} / \mathrm{d}$ (data not shown), and was almost comparable to in the control and DSS groups.

Assessment of Disease Activity Index The disease activity index (DAI) was expressed as the sum of the scores assigned to reflect the following: body weight loss $(0=<5$, $1=5-10,2=11-15$, and $3=16-20 \%)$, stool consistency $(0=$ normal, $1=$ soft but still formed, $2=$ very soft, and $3=$ diarrhea), and rectal bleeding $(0=$ no blood, $1=$ occult blood in stool, $2=$ trace of blood visible in stool, and $3=$ rectal bleeding). ${ }^{32)}$ The minimum DAI score was 0 , and the maximum one was 9 . The DAI scoring was carried out by two independent investigators who were blind as to the experimental groups.

Macroscopic and Histological Evaluation At the end of DSS treatment (day 10), mice were perfused transcardially with $4 \%$ paraformaldehyde in $0.1 \mathrm{~m}$ phosphate buffer $(\mathrm{pH} 7.4)$ containing $0.2 \%$ picric acid under deep anesthesia (pentobarbital sodium, $25 \mathrm{mg} / \mathrm{kg}$, i.p.), and then the entire colon (from the caecum to the anus) was removed, and the colon length was determined. Thereafter, following additional overnight immersion in $4 \%$ paraformaldehyde at $4^{\circ} \mathrm{C}$, the tissues were immersed in a $30 \%$ sucrose solution at $4^{\circ} \mathrm{C}$ overnight, and then cut into $10 \mu \mathrm{m}$ frozen sections and stained with haematoxylin and eosin (HE), photomicrographs being obtained under a light microscope (BX40; Olympus, Tokyo, Japan) equipped with a digital camera (moticam 2000; Shimadzu, Kyoto, Japan).

Histological scoring was performed on the basis of 3 parameters: the severity of inflammation, crypt damage and ulceration. $^{35)}$ Each parameter was scored as follows: inflammation: rare inflammatory cells in the lamina propria (score 0 ), increased number of granulocytes in the lamina propria (score 1), confluence of inflammatory cells extending into the submucosa (score 2), and transmural extension of the inflammatory infiltrate (score 3); crypt damage: intact crypts (score 0 ), loss of the basal one-third (score 1), loss of the basal two- 
thirds (score 2), entire crypt loss (score 3), a change of the epithelial surface with erosion (score 4), and confluent erosion (score 5); ulceration: an absence of ulcer (score 0), 1 or 2 foci of ulcerations (score 1), 3 or 4 foci of ulcerations (score 2), and confluent or extensive ulceration (score 3 ). These values were added to give a maximal histological score of 11 . A minimum of 2 sections of different parts of the distal colon per animal were scored. This scoring was carried out by two independent investigators who were blind as to the experimental groups.

Determination of Colonic Magnesium Contents According to the previous report, ${ }^{36)}$ we measured the magnesium concentrations in mouse colonic feces obtained on day 10 . Feces were subjected to a wet-ashing process involving nitric acid, perchloric acid and hydrogen peroxide at $200-250^{\circ} \mathrm{C}$, and the ashed samples were dissolved in $5 \mathrm{~mL}$ of $5 \%$ nitric acid followed by the addition of $6 \mu \mathrm{L}$ of a $40 \mathrm{ppm}$ indium solution as an internal standard. The magnesium concentrations were measured using an inductively coupled plasma mass spectrometer (ICP-MS, Agilent 7700X ICP-MS; Agilent Technologies, CA, U.S.A.). Standard curves for determination of magnesium concentrations were prepared by dilution of multielement standard solution BM (Wako).

Immunohistochemistry As reported previously, ${ }^{37)}$ after washing with ice-cold Sórensen's phosphate-buffered saline (Sórensen's PBS; $19 \mathrm{~mm} \mathrm{NaH} \mathrm{PO}_{4}$ and $81 \mathrm{~mm} \mathrm{Na} \mathrm{HPO}_{4}, \mathrm{pH}$ 7.4), the colonic free-floating sections were treated with a blocking buffer ( $1 \%$ donkey serum, $0.3 \%$ triton $\mathrm{X}-100,0.3 \%$ bovine serum albumin and $0.05 \%$ sodium azide in PBS) at $4^{\circ} \mathrm{C}$. Then, the sections were immunoreacted with primary antibodies in the blocking buffer for $3 \mathrm{~d}$ at $4^{\circ} \mathrm{C}$, followed by incubation for a day at $4^{\circ} \mathrm{C}$ with secondary antibodies in the blocking buffer. The primary antibodies used were mouse anti-mast cell tryptase antibodies (1:50; Cat. No. sc-59585, Santa Cruz, CA, U.S.A.) and rabbit anti-P2X7 receptor antibodies (1:100, Cat No. APR004, Alomone Labs., Jerusalem, Israel), and the secondary ones were donkey anti-mouse immunoglobulin $\mathrm{G}$ ( $\mathrm{IgG})$ antibodies conjugated with Alexa Fluor $^{\circledR} 594$ (1:1000; Cat. No. 21203, Life Technologies, CA, U.S.A.) and donkey anti-rabbit IgG antibodies conjugated with Alexa Fluor ${ }^{\circledR} 488$ (1:1000; Cat. No. 21206, Life Technologies). For all immunostaining, a negative control, which was prepared by omitting the primary antibodies, was prepared, and the reproducibility of immunostaining was confirmed by assessing sections from 3 or 4 rats per immunostaining. The sections were mounted on glass slides and then enclosed using a Prolong ${ }^{\circledR}$ antifade kit (Life Technologies). Photomicrographs were obtained under a confocal laser microscope (LSM510META; Carl Zeiss, Jena, Germany). Fluorescence intensity was measured using the histogram program of the Photoshop software (Adobe Systems, CA, U.S.A.).

Statistical Analysis All data were expressed as means \pm standard deviation (S.D.). Comparisons among groups, of which the populations were considered to have a normal distribution, were performed by means of the Tukey-Kramer test, and differences with a $p$-value of 0.05 or less were considered statistically significant.

\section{RESULTS}

Colitis Symptoms In DSS-treated mice, the DAI score increased day by day up to day 10 , and significant differences between the control and DSS groups were detected from day 3 (Fig. 1a). The mice administered BBG $(250 \mathrm{mg} / \mathrm{kg}$, p.o.) also showed a time-dependent increase of the DAI score, but the score was partially, but significantly, less than that in the DSS group, and the same profiles were found in the mice p.o. administered with $\mathrm{MgCl}_{2}$ at the doses of 100 and $500 \mathrm{mg} / \mathrm{kg}$, the values on days 9 and 10 in the $100 \mathrm{mg} / \mathrm{kg}$ group being significantly lower. With ad libitum ingestion of $\mathrm{MgCl}_{2}$ (800 ppm) and RDSW, the DAI scores tended to be lower than those in the control group, but significant differences were not detected. Figure 1b shows the colon length in these mice. The mice treated with DSS had a significantly shorter colon length compared to the control group. As the BBG group, in contrast, the colon in the $\mathrm{MgCl}_{2}$ p.o. administration groups, 100 and $500 \mathrm{mg} / \mathrm{kg}$ doses, was significantly greater than that in the DSS group. The ad libitum ingestion of RDSW significantly prevented shortening of the colon length, while there was no alteration in the colon length in the $\mathrm{MgCl}_{2}$ ad libitum ingestion group. These findings indicated that p.o. administration of $\mathrm{MgCl}_{2}$ prevented the progress of DSS-induced colitis partially as in the case of BBG administration, and almost the same prophylactic effect was found on ad libitum ingestion of RDSW, but it seemed to be less than in the case of $\mathrm{MgCl}_{2}$ p.o. administration.

Figure 2 shows the magnesium contents in the colons of the control, DSS $\mathrm{MgCl}_{2}$ and RDSW groups. Compared to the control group, the DSS group showed lower magnesium contents in the feces, this being considered to be the result of diarrhea. The p.o. administration $\mathrm{MgCl}_{2}$ significantly increased the magnesium contents in the feces and there was no difference in them between the doses of 100 and $500 \mathrm{mg} / \mathrm{kg}$. The ad libitum ingestion of RDSW increased the magnesium contents in mouse colonic feces, while there was tendency of an increase of them on ad libitum ingestion of $\mathrm{MgCl}_{2}$ ( $\left.800 \mathrm{ppm}\right)$. Therefore, it is considered that the prophylactic effects of $\mathrm{MgCl}_{2}$ p.o. administration and RDSW ad libitum ingestion on DSSinduced colitis are due, at least in part, to the increase in the magnesium content in mouse colons.

Histological Alterations To determine whether or not the p.o. administration of a $\mathrm{MgCl}_{2}$ solution and ad libitum ingestion of RDSW prevent histological and immunohistochemical alterations induced by DSS treatment, we performed a second set of experiments. In this set, we confirmed that the DSS treatment induced the elevation of the DAI scores and the shortening of the colon, and these alterations were partially prevented by $\mathrm{MgCl}_{2}$ p.o. administration $(100 \mathrm{mg} / \mathrm{kg}$ ) and ad libitum ingestion of RDSW (data not shown), as in the first set of experiments shown in Figs. 1 and 2.

As shown in Fig. 3, histological examination revealed that DSS treatment induced severe colitis, which was characterized by extensive disruption of the epithelium, massive loss of goblet cells and diffuse loss of crypts, and these changes partially disappeared on BBG administration. Similarly, the p.o. administration of $\mathrm{MgCl}_{2}$ and the ad libitum ingestion of RDSW reduced the DSS-induced increase of histological scores with decreases of the inflammatory infiltration and crypt damage.

Colonic Accumulation of Mast Cells Finally, we evaluated the accumulation of mast cells in the colons of mice (Fig. 4). Treatment of mice with DSS increased significantly the number of mast cells in the colon with increase of P2X7Rimmunopositive mast cells. As $\mathrm{BBG}$, both the $\mathrm{MgCl}_{2}$ p.o. 
(a)

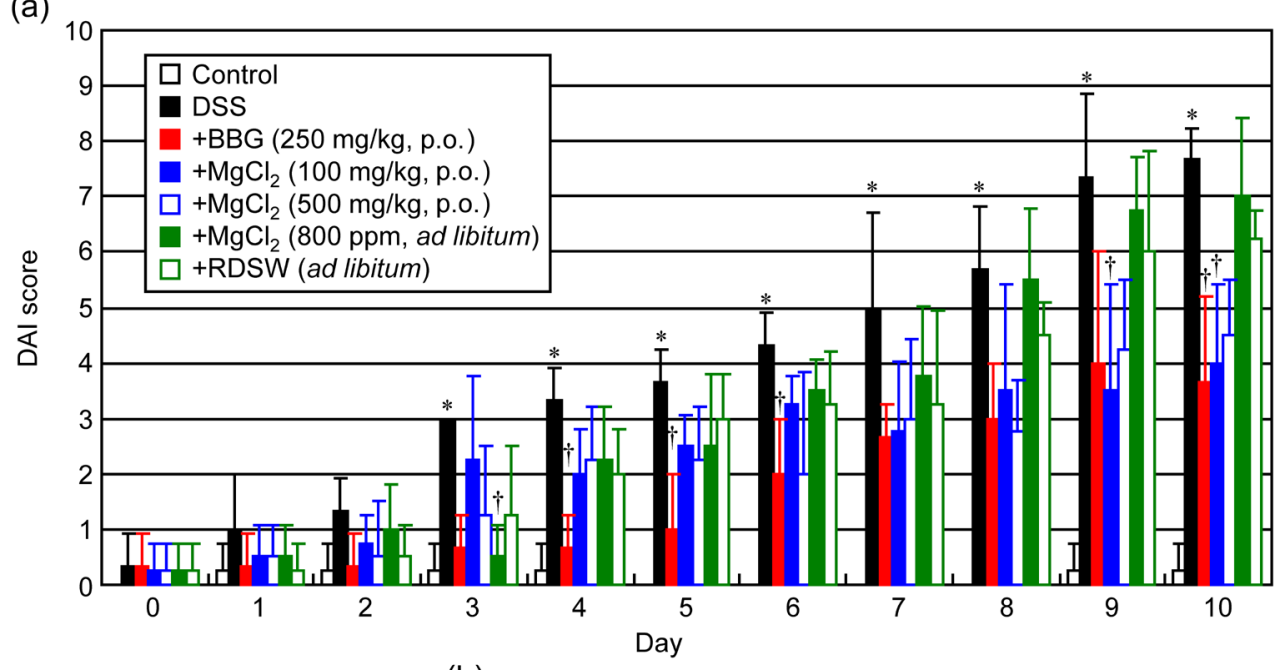

(b)

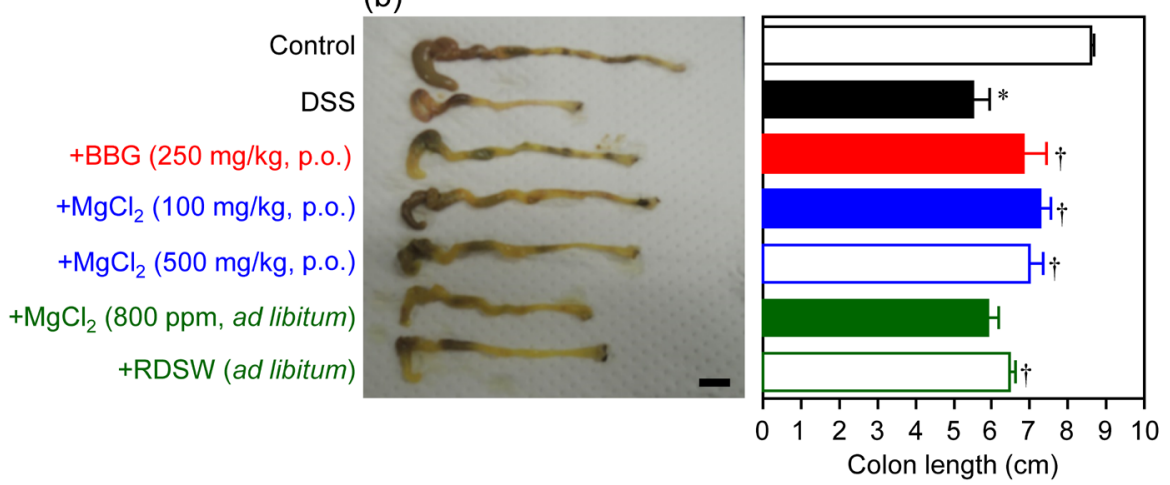

Fig. 1. Effect of $\mathrm{MgCl}_{2}$ or RDSW Administration on the DAI Score (a) and Colon Length (b) in DSS-Treated Mice

To induce IBD, mice were treated with $3 \%$ DSS ad libitum for $10 \mathrm{~d}$. A $\mathrm{MgCl}_{2}$ or BBG solution was administered p.o. at the dose of 100 or $500 \mathrm{mg} / \mathrm{kg}$, or $250 \mathrm{mg} / \mathrm{kg}$, respectively, once a day from a day before initiation of the DSS administration for 11 times. The $\mathrm{MgCl}_{2}$ solution (800 ppm) or RDSW was administered to mice ad libitum from a day before initiation of the DSS administration for $11 \mathrm{~d}$. Evaluation of DAI was performed every day before the administration, and the colon length was measured on day 10 . In panel b, a representative photograph of colons of three to four mice in each group is shown. Each point/bar represents the mean \pm S.D. $(N=3-4)$. Scale bar $=1 \mathrm{~cm}$. ${ }^{*} p<0.05$ (vs. control). ${ }^{\dagger} p<0.05$ (vs. DSS).

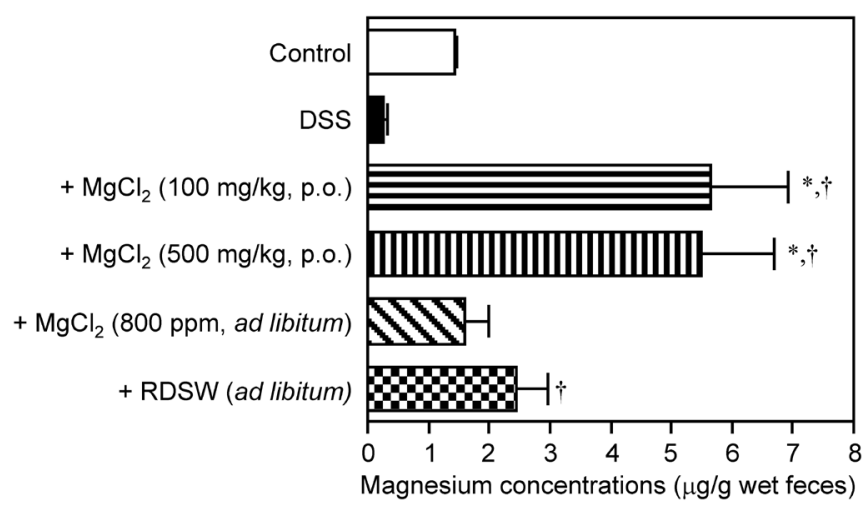

Fig. 2. Effect of $\mathrm{MgCl}_{2}$ or RDSW Administration on the Colonic Magnesium Content in DSS-Treated Mice

To induce IBD, mice were treated with $3 \%$ DSS ad libitum for $10 \mathrm{~d} . \mathrm{A} \mathrm{MgCl}_{2}$ solution was administered p.o. at the dose of 100 or $500 \mathrm{mg} / \mathrm{kg}$ once a day from a day before initiation of the DSS administration for 11 times. The $\mathrm{MgCl}_{2}$ solution $(800 \mathrm{ppm})$ or RDSW was administered to mice ad libitum from a day before initiation of the DSS administration for $11 \mathrm{~d}$. Colonic magnesium contents were measured on day 10 with an ICP-MS. Each bar represents the mean \pm S.D. $(N=3-4)$ ${ }^{*} p<0.05$ (vs. control). ${ }^{\dagger} p<0.05$ (vs. DSS).

administration and ad libitum ingestion of RDSW decreased the colonic accumulation of mast cells and the proportions of P2X7R-immunopositive cells in them.

\section{DISCUSSION}

In this study, we demonstrated that in addition to p.o. administration of $\mathrm{MgCl}_{2}$, ad libitum ingestion of $\mathrm{RDSW}$, which contains a high concentration of magnesium, increased the colonic magnesium content and prevented partially, but significantly, the development of DSS-induced experimental colitis in mice, and that these prophylactic effects were due, in part, to inhibition of the activation/accumulation of colonic mast cells including P2X7R-immunopositive cells as the initiation phase of colitis development. Together with the finding that an increase in the numbers of P2X7R-expressing mast cells is found in the colons of not only mice with colitis but also patients with Crohn's disease, ${ }^{16)}$ we believe that these findings should provide a novel strategy for the development of a prophylactic approach for IBD symptoms such as Crohn's disease.

Previously, several approaches for prevention of development of experimental colitis focusing on P2X7R blockade were successful, but the antagonists/antibodies for P2X7R were administered via parenteral routes such as i.p. and intrarectal (i.r.) administration. ${ }^{16-18)}$ In addition, Marques et al. reported that twice intra-colonic administration of $\mathrm{BBG}$ at $40 \mathrm{mg} / \mathrm{kg}$ on days -1 and 3 could not prevent the development of DSS-induced colitis in rats, suggesting systemic P2X7R 
(a)

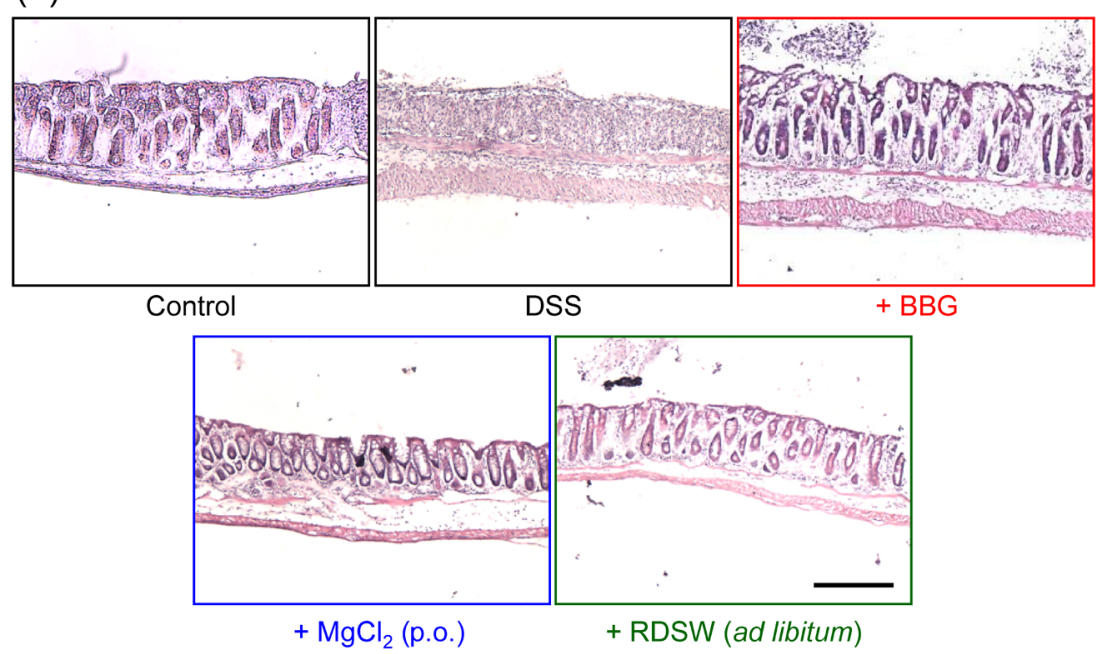

(b)

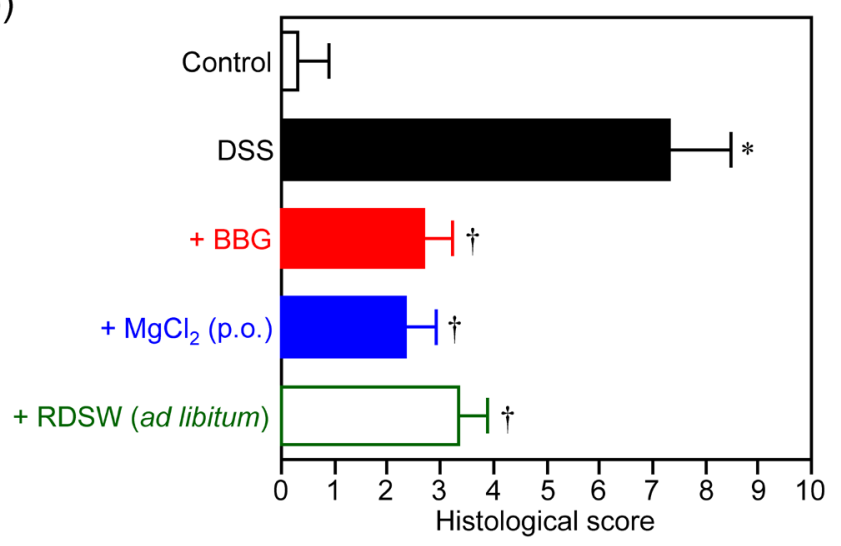

Fig. 3. Effect of $\mathrm{MgCl}_{2}$ or RDSW Administration on the Colonic Histology in DSS-Treated Mice

To induce IBD, mice were treated with $3 \% \mathrm{DSS}$ ad libitum for $10 \mathrm{~d}$. A $\mathrm{MgCl}_{2}$ or $\mathrm{BBG}$ solution was administered p.o. at the dose of $100 \mathrm{mg} / \mathrm{kg}$ or $250 \mathrm{mg} / \mathrm{kg}$, respectively, once a day from a day before initiation of the DSS administration for 11 times. RDSW was administered to mice ad libitum from a day before initiation of the DSS administration for $11 \mathrm{~d}$. Colonic histology was evaluated on day 10 with HE staining. Representative photomicrographs of three mice in each group (a) and the quantitative results (b) are shown. Each bar represents the mean \pm S.D. $(N=3)$. Scale bar $=50 \mu \mathrm{m} .{ }^{*} p<0.05$ (vs. control). ${ }^{\dagger} p<0.05$ ( $v s$. DSS).

blockade was needed. ${ }^{17)}$ In our preliminary experiments, in contrast, we found that the i.p. administration of BBG at 50 and $100 \mathrm{mg} / \mathrm{kg}$ based on the dose of Marques et al. had no apparent effects on the DSS-induced IBD symptoms in mice (data not shown). Although differences in experimental conditions including species difference might explain this discrepancy, the details are not clear. However, as aforementioned, when the colonic concentrations of P2X7R blockers reach effective ones such as $\mathrm{IC}_{50}$ values on their p.o. administration, it is reasonable to expect that they should show preventive effects on colitis by inhibition of ATP-P2X7R-mediated activation/accumulation of colonic mast cells, followed by induction of not only inflammatory cytokines, but also chemokines and leukotrienes for infiltration of neutrophils into the colon, leading to subsequent exacerbation of intestinal inflammation. ${ }^{16)}$ In fact, we found that as the p.o. administration of $\mathrm{BBG}$, the p.o. administration of $\mathrm{MgCl}_{2}$ and ad libitum ingestion of RDSW is effective to prevent the DSS-induced colitis. These prophylactic effects on the DSS-induced colitis in mice is considered to be due, at least in part, to inhibition of the colonic accumulation of P2X7R-expressing mast cells, because the accumulation is primed by activation of $\mathrm{P} 2 \mathrm{X} 7 \mathrm{R}$ expressed by them, ${ }^{16}$ ) although there is a possibility that mechanisms other than P2X7R inhibition might be involved in the BBG- and magnesium-mediated prevention of the DSSinduced colitis. Recently, we reported that there is no species difference in the sensitivity of P2X7R to magnesium between humans and mice. ${ }^{23)}$ Overall, it is suggested that daily ingestion of magnesium might have a prophylactic effect in IBD patients through inhibition of inflammatory conditions including P2X7R-induced mast cell activation.

Administration of magnesium and RDSW prevented the development of the DSS-induced colitis symptoms and histological changes, but it was only partial, although its efficacy was statistically significant. In the studies of Marques et al. ${ }^{17)}$ and Wan et al., ${ }^{18)}$ the i.p. administration of P2X7R antagonists had significant, but partial, preventive effects on experimental colitis, while on i.r. administration of the P2X7R antibodies, the colitis symptoms in mice recovered to those in the control group, ${ }^{16)}$ suggesting that activation of colonic mast cells via P2X7R activation has to be almost completely inhibited for clear prevention of colitis onset. In addition, colitis symptoms have been shown to be exacerbated by neutrophil infiltration induced by chemokines released from activated colonic mast cells. ${ }^{16)}$ Thus, it is considered that with our experimental protocols, p.o. administration of P2X7R blockers had partial 
(a)
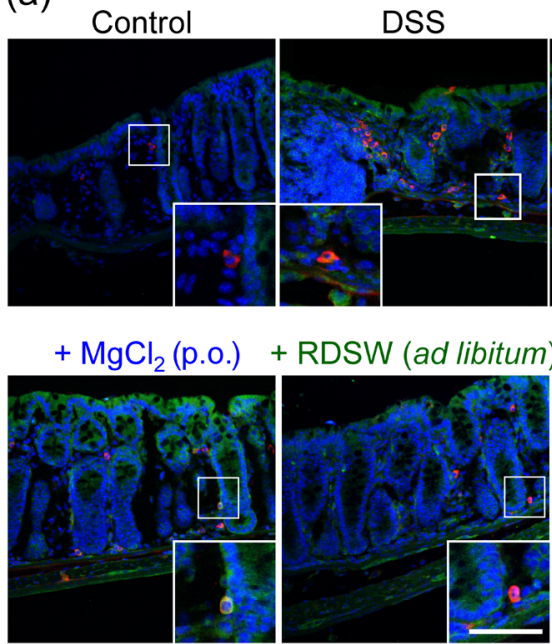

+ RDSW (ad libitum)

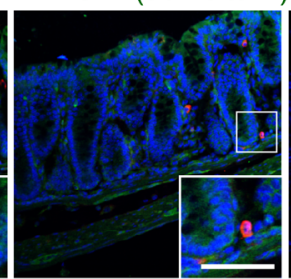

(b)

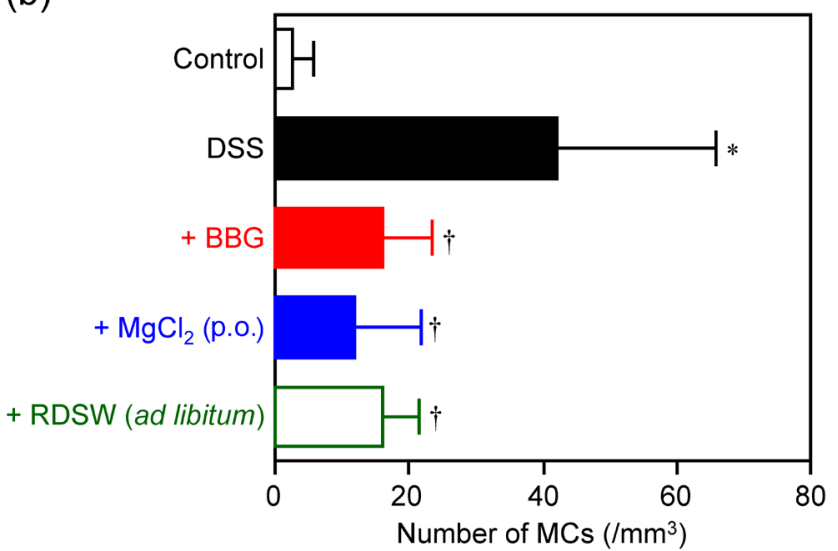

(c)

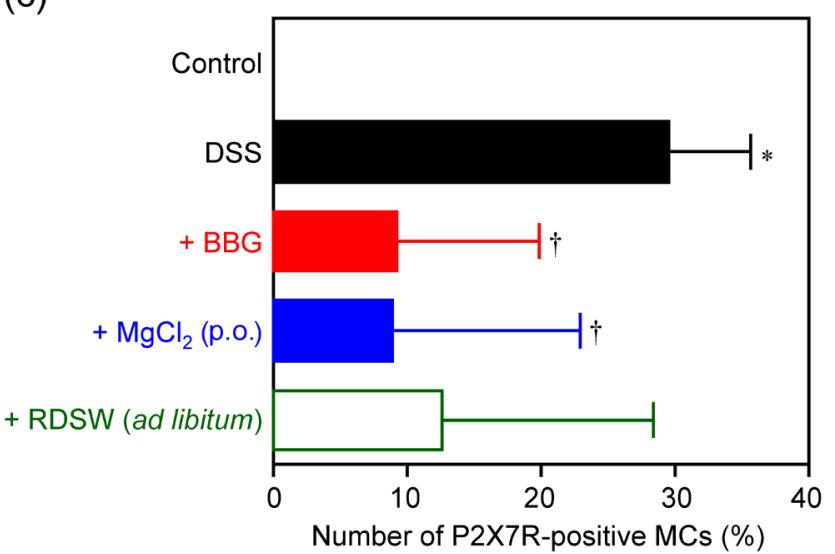

Fig. 4. Effect of $\mathrm{MgCl}_{2}$ or RDSW Administration on Colonic Mast Cell Accumulation in DSS-Treated Mice

To induce IBD, mice were treated with $3 \%$ DSS ad libitum for $10 \mathrm{~d}$. $\mathrm{A} \mathrm{MgCl}$ or BBG solution was administered p.o. at the dose of $100 \mathrm{mg} / \mathrm{kg}$ or $250 \mathrm{mg} / \mathrm{kg}$, respectively, once a day from a day before initiation of the DSS administration for 11 times. RDSW was administered to mice ad libitum a day before initiation of the DSS administration for $11 \mathrm{~d}$. The numbers of total and P2X7R-immunopositive mas cells were determined on day 10 by immunohistochemistry with counterstaining nuclei with Hoechst33258 $(10 \mu \mathrm{g} / \mathrm{mL})$. Representative photomicrographs of three mice in each group (a) and the quantitative results (b, c) are shown. Each bar represents the mean \pm S.D. $(N=3)$. Scale bar $=50 \mu \mathrm{m} .{ }^{*} p<0.05$ (vs. control). ${ }^{\dagger} p<0.05$ (vs. DSS).

preventive effects on the DSS-induced colitis.

While ad libitum ingestion of RDSW partially prevented the development of DSS-induced colitis, ad libitum ingestion of a $\mathrm{MgCl}_{2}$ solution, of which the concentration of $800 \mathrm{ppm}$ was the same as that of RDSW, had no effect on the colitis symptoms. One of the possible reasons is considered to be the lower magnesium concentration in the colon on ad libitum ingestion of $\mathrm{MgCl}_{2}$ solution ( $800 \mathrm{ppm}$ ) group than that in the ad libitum ingestion of RDSW group, although details of this difference are unknown. In addition to magnesium, RDSW contains calcium at the concentration of $78.3 \mathrm{ppm}(1.85 \mathrm{~mm})$ as another DMC. In our previous study, calcium exhibited an inhibitory effect on P2X7R activation, and its inhibitory effect was the weakest among the DMCs examined, its $\mathrm{IC}_{50}$ value being 2 or more $\mathrm{mm}^{23}$ ) Thus, the concentration of calcium in RDSW is low to inhibit P2X7R activation, but interaction of magnesium and calcium such as an additive/synergistic effect might explain the difference between the $\mathrm{MgCl}_{2}$ solution and RDSW. This might be supported by the findings that nevertheless the colonic magnesium concentration in RDSW-ingested mice was approximately half of that in $\mathrm{MgCl}_{2}$-p.o. administered ones, their preventive effects on the DSS-induced colitis symptoms were almost the same (Figs. 2, 3). Further detailed investigations are needed to clarify this.

There is the possibility that administration of high doses of magnesium may induce diarrhea and hypermagnesemia. As described in Materials and Methods, p.o. administration of $\mathrm{MgCl}_{2}$ solution at the dose of $500 \mathrm{mg} / \mathrm{kg}$, and ad libitum ingestion of $\mathrm{RDSW}$ and $\mathrm{MgCl}_{2}$ solution (800 ppm) did not cause diarrhea in mice (data not shown). Furthermore, under the condition shown in Fig. 1, the scores of stool consistency of mice in control, DSS, BBG, $\mathrm{MgCl}_{2}\left(100 \mathrm{mg} / \mathrm{kg}\right.$, p.o.), $\mathrm{MgCl}_{2}$ (500 mg/kg, p.o.), $\mathrm{MgCl}_{2}$ (800 ppm, ad libitum) and RDSW (ad libitum) groups on day 10 were $0.25 \pm 0.50,2.33 \pm 0.58$, $2.33 \pm 0.58,2.00 \pm 0.82,2.75 \pm 0.5,2.50 \pm 0.58$ and $2.50 \pm 0.58$, respectively, and on other days, there was no apparent increase in the scores by administration/ingestion of magnesium. Thus, we think that administration/ingestion of magnesium under the condition adopted in this study does not induce diarrhea in mice. As for hypermagnesemia, we did not measure the plasma magnesium concentrations in this study, but there seems to be no or negligible possibility to induce hypermagnesemia in $\mathrm{MgCl}_{2}$ - and $\mathrm{RDSW}$-administered mice, because hypermagnesemia is known to be found in magnesium-administered patients with renal dysfunction and constipation.

Very recently, colonic inflammation with colonic accumulation of macrophages induced by ingestion of a high-fat diet endowed mice with insulin resistance in an intestinal $\mathrm{Ccl} 2$ / Ccr2-dependent manner. ${ }^{38)}$ Since macrophages are representative cells expressing P2X7R highly, ${ }^{9-12)}$ and Kurashima et al., demonstrated that mast cells treated with ATP showed the expression of chemokines such as $\left.\mathrm{Ccl} 2,{ }^{16}\right)$ it is suggested that administration of magnesium might inhibit the development of high-fat diet-induced insulin resistance, leading to prevention of onset of lifestyle-related type II diabetes mellitus.

\section{CONCLUSION}

Here, we demonstrated that p.o. administration and ad libitum ingestion of magnesium had preventive effects on the development of experimental colitis and that an underlying mechanism was inhibition of colonic mast cell activation via $\mathrm{P} 2 \mathrm{X} 7 \mathrm{R}$. As there is no species difference in the inhibitory effect of magnesium between humans and mice, ${ }^{23)}$ this prophylactic effect of magnesium on colitis might be obtained in IBD patients. 
Acknowledgments A part of this study was financially supported by a Grant-in-Aid for Scientific Research (C) (16K08284) from the Japan Society for the Promotion of Science (JSPS), the Ministry of Education, Culture, Sports, Science and Technology of Japan (MEXT)-Supported Program for the Strategic Research Foundation at Private Universities, 2012-2016 (S1201008), and Ako Kasei Co., Ltd.

Conflict of Interest Kazuki Nagasawa received a research Grant from Ako Kasei Co., Ltd.

\section{REFERENCES}

1) Baumgart DC, Carding SR. Inflammatory bowel disease: cause and immunobiology. Lancet, 369, 1627-1640 (2007).

2) Podolsky DK. Inflammatory bowel disease. N. Engl. J. Med., 347, 417-429 (2002)

3) Cho JH. The genetics and immunopathogenesis of inflammatory bowel disease. Nat. Rev. Immunol., 8, 458-466 (2008).

4) Xavier RJ, Podolsky DK. Unravelling the pathogenesis of inflammatory bowel disease. Nature, 448, 427-434 (2007).

5) Arseneau KO, Tamagawa H, Pizarro TT, Cominelli F. Innate and adaptive immune responses related to IBD pathogenesis. Curr. Gastroenterol. Rep., 9, 508-512 (2007).

6) Brown SJ, Mayer L. The immune response in inflammatory bowel disease. Am. J. Gastroenterol., 102, 2058-2069 (2007).

7) Graham DB, Becker CE, Doan A, Goel G, Villablanca EJ, Knights D, Mok A, Ng AC, Doench JG, Root DE, Clish CB, Xavier RJ. Functional genomics identifies negative regulatory nodes controlling phagocyte oxidative burst. Nat. Commun., 6, 7838 (2015).

8) Coutinho-Silva R, Monteiro da Cruz C, Persechini PM, Ojcius DM. The role of $\mathrm{P} 2$ receptors in controlling infections by intracellular pathogens. Purinergic Signal., 3, 83-90 (2007).

9) Abderrazak A, Syrovets T, Couchie D, El Hadri K, Friguet B, Simmet T, Rouis M. NLRP3 inflammasome: from a danger signal sensor to a regulatory node of oxidative stress and inflammatory diseases. Redox Biol., 4, 296-307 (2015).

10) Kahlenberg JM, Dubyak GR. Mechanisms of caspase-1 activation by P2X7 receptor-mediated $\mathrm{K}^{+}$release. Am. J. Physiol. Cell Physiol., 286, C1100-C1108 (2004).

11) Luna-Gomes $\mathrm{T}$, Santana PT, Coutinho-Silva R. Silica-induced inflammasome activation in macrophages: role of ATP and P2X7 receptor. Immunobiology, 220, 1101-1106 (2015).

12) Ferrari D, Pizzirani C, Adinolfi E, Lemoli RM, Curti A, Idzko M, Panther E, Di Virgilio F. The P2X7 receptor: a key player in IL-1 processing and release. J. Immunol., 176, 3877-3883 (2006).

13) Deaglio S, Robson SC. Ectonucleotidases as regulators of purinergic signaling in thrombosis, inflammation, and immunity. $A d v$. Pharmacol., 61, 301-332 (2011).

14) Eltzschig HK, Sitkovsky MV, Robson SC. Purinergic signaling during inflammation. N. Engl. J. Med., 367, 2322-2333 (2012).

15) Wiley JS, Sluyter R, Gu BJ, Stokes L, Fuller SJ. The human P2X7 receptor and its role in innate immunity. Tissue Antigens, 78, 321332 (2011).

16) Kurashima $Y$, Amiya T, Nochi T, Fujisawa K, Haraguchi T, Iba H, Tsutsui H, Sato S, Nakajima S, Iijima H, Kubo M, Kunisawa J, Kiyono $\mathrm{H}$. Extracellular ATP mediates mast cell-dependent intestinal inflammation through P2X7 purinoceptors. Nat. Commun., 3, 1034 (2012).

17) Marques CC, Castelo-Branco MT, Pacheco RG, Buongusto F, do Rosario A Jr, Schanaider A, Coutinho-Silva R, de Souza HS. Prophylactic systemic P2X7 receptor blockade prevents experimental colitis. Biochim. Biophys. Acta, 1842, 65-78 (2014).

18) Wan P, Liu X, Xiong Y, Ren Y, Chen J, Lu N, Guo Y, Bai A. Extracellular ATP mediates inflammatory responses in colitis via P2X7 receptor signaling. Sci. Rep., 6, 19108 (2016).

19) Chessell IP, Simon J, Hibell AD, Michel AD, Barnard EA, Humphrey PP. Cloning and functional characterisation of the mouse P2X7 receptor. FEBS Lett., 439, 26-30 (1998)

20) Jiang LH. Inhibition of P2X(7) receptors by divalent cations: old action and new insight. Eur. Biophys. J., 38, 339-346 (2009).

21) Surprenant A, Rassendren F, Kawashima E, North RA, Buell G. The cytolytic P2Z receptor for extracellular ATP identified as a P2X receptor (P2X7). Science, 272, 735-738 (1996).

22) Virginio C, Church D, North RA, Surprenant A. Effects of divalent cations, protons and calmidazolium at the rat $\mathrm{P} 2 \mathrm{X} 7$ receptor. Neuropharmacology, 36, 1285-1294 (1997).

23) Fujiwara M, Ohbori K, Ohishi A, Nishida K, Uozumi Y, Nagasawa $\mathrm{K}$. Species difference in sensitivity of human and mouse P2X7 receptors to inhibitory effects of divalent metal cations. Biol. Pharm. Bull., 40, 375-380 (2017)

24) Acuña-Castillo C, Morales B, Huidobro-Toro JP. Zinc and copper modulate differentially the $\mathrm{P} 2 \mathrm{X} 4$ receptor. $J$. Neurochem., 74, 1529-1537 (2000).

25) Clyne JD, LaPointe LD, Hume RI. The role of histidine residues in modulation of the rat $\mathrm{P} 2 \mathrm{X}(2)$ purinoceptor by zinc and $\mathrm{pH} . J$. Physiol., 539, 347-359 (2002).

26) Nakazawa K, Ohno Y. Effects of neuroamines and divalent cations on cloned and mutated ATP-gated channels. Eur. J. Pharmacol., 325, 101-108 (1997).

27) Wildman SS, King BF, Burnstock G. $\mathrm{Zn}^{2+}$ modulation of ATPresponses at recombinant $\mathrm{P} 2 \mathrm{X} 2$ receptors and its dependence on extracellular pH. Br. J. Pharmacol., 123, 1214-1220 (1998).

28) Wildman SS, King BF, Burnstock G. Modulatory activity of extracellular $\mathrm{H}^{+}$and $\mathrm{Zn}^{2+}$ on ATP-responses at $\mathrm{rP} 2 \mathrm{X} 1$ and $\mathrm{rP} 2 \mathrm{X} 3$ receptors. Br. J. Pharmacol., 128, 486-492 (1999).

29) Wildman SS, King BF, Burnstock G. Modulation of ATP-responses at recombinant $\mathrm{rP} 2 \mathrm{X} 4$ receptors by extracellular $\mathrm{pH}$ and zinc. $\mathrm{Br}$. $J$. Pharmacol., 126, 762-768 (1999).

30) Xiong K, Peoples RW, Montgomery JP, Chiang Y, Stewart RR, Weight FF, Li C. Differential modulation by copper and zinc of P2X2 and P2X4 receptor function. J. Neurophysiol., 81, 2088-2094 (1999).

31) Ako Kasei Co., Ltd. "Amami's Water ${ }^{\mathbb{Q}} /$ Water Hardness 1000.": 〈http://web.ako-kasei.co.jp/catalogue/shinsousui/amaminomizu_1000/s, cited 20 January, 2017.

32) Wirtz $\mathrm{S}$, Neufert $\mathrm{C}$, Weigmann B, Neurath MF. Chemically induced mouse models of intestinal inflammation. Nat. Protoc., 2, 541-546 (2007).

33) Jiang LH, Mackenzie AB, North RA, Surprenant A. Brilliant blue G selectively blocks ATP-gated rat P2X(7) receptors. Mol. Pharmacol., 58, 82-88 (2000).

34) Apolloni S, Amadio S, Parisi C, Matteucci A, Potenza RL, Armida M, Popoli P, D’Ambrosi N, Volonte C. Spinal cord pathology is ameliorated by P2X7 antagonism in a SOD1-mutant mouse model of amyotrophic lateral sclerosis. Dis. Model. Mech., 7, 1101-1109 (2014).

35) Theiss AL, Vijay-Kumar M, Obertone TS, Jones DP, Hansen JM, Gewirtz AT, Merlin D, Sitaraman SV. Prohibitin is a novel regulator of antioxidant response that attenuates colonic inflammation in mice. Gastroenterology, 137, 199-208, 208.e1-208.e6 (2009).

36) Ohishi A, Nishida K, Yamanaka Y, Miyata A, Ikukawa A, Yabu M, Miyamoto K, Bansho S, Nagasawa K. Oxaliplatin alters expression of T1R2 receptor and sensitivity to sweet taste in rats. Biol. Pharm. Bull., 39, 578-586 (2016)

37) Nishida K, Dohi Y, Yamanaka Y, Miyata A, Tsukamoto K, Yabu M, Ohishi A, Nagasawa K. Expression of adenosine A2b receptor in rat type II and III taste cells. Histochem. Cell Biol., 141, 499-506 (2014).

38) Kawano Y, Nakae J, Watanabe N, Kikuchi T, Tateya S, Tamori Y, Kaneko M, Abe T, Onodera M, Itoh H. Colonic pro-inflammatory macrophages cause insulin resistance in an intestinal Ccl2/Ccr2dependent manner. Cell Metab., 24, 295-310 (2016). 